\title{
Remote and Virtual Labs @ exp.at'11
}

http://dx.doi.org/10.3991/ijoe.v8iS2.2040

exp.at'11, the first event of Experiment@, a new International Conference series devoted to online experimentation, had as scope to contribute to the world capabilities in online experimentation and in particular in remote and virtual labs, fostering the collaborative work in emergent technologies.

The conference was held at Calouste Gulbenkian Foundation (Lisbon, Portugal), the main sponsor of the conference.

exp.at'11 provided a two-day forum of discussion and collaboration between academics, researchers, K-12 teachers and industry, trying to bridge the gap between academic applications and results as well as real world needs and experiences.

Three invited presentations were made: “The new Challenges in Engineering Education and the Role of Online Laboratories” by Prof. Michael Auer, Carinthia University, Austria; “Bridging the Divide and Integrating Technologies: Investigating Developments, Possibilities and Benefits of Virtual and Remote Laboratories for Education in Africa” by Prof. James Uhomoibhi, University of Ulster, UK; “Virtually Touching: Haptics for Learning” by and Prof. Liliane Machado, U.F. Paraíba, Brazil.

Michael Auer, the president of the International Society for Engineering Education (IGIP), reinforced in his keynote the fundamental aspect of engineering as the link between the Sciences and the Society. Topics as the new engineering disciplines, the new tasks within traditional engineering, the impressive decrease in innovation time life cycles, the new jobs in engineering and many of the important aspects in Engineering Education were briefly addressed, giving emphasis to the internationalization in engineering activity. Between the new challenges in engineering education he pointed out the role of Online Engineering. In this respect the mission of GOLC (Global Online Laboratory Consortium) has been stated. He also conveyed the strong involvement of IGIP in the important tasks of encouraging the use of media in technical teaching and in supporting, between others, the improvement of engineering education in developing countries.

James Uhomoibhi presented a reflection on the Digital Divide, the "division that exists in the world between people and communities who have access to information and communications technology (ICT) and those who do not”, and briefly pointed out its impact. Looking to the e-learning approaches and in particular to Remote and Virtual Labs, James Uhomoibhi summed up their relevance as new valuable tools to be explored everywhere. Particularly he focused on policies and experiences in African Countries. Examples were described as those in Uganda, Nigeria, Tanzania, Tunisia, etc and their visible real benefits were addressed. The existence of highly sophisticated equipment, as is the case of that involved in the Ligo project (Laser Interferometer Gravitational-wave Observatory) was used to reinforce the remote didactic and training possibilities not accessible to everyone in loco.

Liliane Machado in her speech entitled Virtually Touching: Haptics for Learning, focused in this modern tool available at a cost that makes it usable for learning and training purposes. The sense of touch permits a level of computer-based learning immersion which has been proved to contribute for improving the students' integration of complex information. These devices, the haptic devices, can interact with virtual reality applications and convey to the user touch feedback, bringing new capabilities for turning virtual more real. At the present haptic devices are used in many distinct areas from medicine to industry. They have already been introduced in engineering education, too. Types of haptic devices and their main features and options were summarized. The final discussion reviewed how haptics could improve learning tasks.

exp.at'11 activities have promoted professional and scientific interactions for improving discussion and reflections about remote and virtual labs, encouraging the research in the area, allowing the participants the opportunity to present their recent work and experience reports, to take part in open discussions, and providing a final round table with the participation of different experts, namely the president of the Portuguese National Foundation for Scientific Computing.

This special issue of the International Journal of Online Engineering includes some works of this Conference which will be summarized below.

"Design of a flexible hardware interface for multiple remote electronic practical experiments of virtual Laboratory" is concerned with the development of new and flexible hardware interface (FHI) based in an open architecture dedicated to electronic experiments for engineering courses at undergraduate level. The FHI controls practical evaluation boards (PEB). However, the hardware interface has features which make it adaptable to other fields. The software architecture uses the design of web interfaces developed in HTML (CSS) and JavaScript language. Any of the standard browsers can be used to access the experiments. 
"RemoteLabs Platform" is a work focused in reporting preliminary steps in the design and development of a Web application for supporting learning and training activities in the power electronics area: a remote experimentation with electric motors. The new proposed solution highlights the user and the set-up interfaces. The work describes different open source languages, plug-ins and integrated development environments (IDE). All the functionalities, as scheduling the experiment, interaction with the experiment and getting data from the experiment, have been tested; however, the real connection with the electric machine has not yet been performed.

“Software Packages to Support Electrical Engineering Virtual Laboratories” describes a technique for building virtual reality systems for supporting electric circuit theory for learning and training, based in 3D Studio Max, Cinema 4D, Autocad, VizUp, Wirefusion, Flash and Java software packages. The work explains basic details of combining different functionalities in order to get the components and the environments, balancing models resolution and their 3D sizes. The work is still running and therefore it is still not available.

“Using an online remote laboratory for electrical experiments in upper secondary education” reports an example of cooperation established between Swedish higher and upper secondary schools in the use of remote labs in electronics. VISIR is the used architecture. The article stresses the young digital literacy and the interest of taking advantage of it and also points out the role of remote labs as complementary tools for learning activities. This activity has been evaluated and results are also presented and discussed.

“Experiences from Deployment of Remotely-Accessible Robotics Laboratory” presents a software and hardware based solution for the technical challenge of maintenance-free operation of robots in an online robotic laboratory where the user can remotely control the robots over the internet and observe their movements. The Lab has a local supervision system to monitor the robots and automatically support some operation conditions such as the energy charging process or the lighting requirements to ensure good visibility through the cameras. The paper describes the hardware and software developed and shows the lab’s potential for different educational contexts.

“Hey Fellows, We Shrunk the Server" presents a solution for the server of a remote lab platform based on open source software, a cheap router and a Linux distribution targeted at embedded systems. The authors describe the main server requirements and how their proposal meets them, emphasizing the easy software development, the use of low cost hardware and the security and flexibility aspects. The paper shows the implementation of a remote lab for the test of printed circuit boards and the programming/configuration of programmable logic devices and memories through a JTAG interface.

“Using a Web Platform Developed for the Teaching of Chemical Processes to Reach Secondary School Students” describes the components of a web platform in the Chemical Engineering area targeted at the pre-university education level. The paper presents the portal architecture globally and the sections for "Secondary Schools" in more detail concerning Physics and Chemistry concepts and applications, including some simulations of chemical processes and quizzes to assess knowledge acquisition. A strategy for the dissemination of the portal towards secondary schools is also explained.

“A Remote and Virtual Lab with Experiments for Secondary Education, Engineering and Lifelong Learning Courses" presents the main aspects of a web platform in development to support diverse remote and virtual experiments for high school and engineering students or lifelong learning trainees. The paper describes the conceptualization and architecture of the platform and some of the experiences. The integration of the experiments within an intelligent tutoring system with adaptability to different users' type is also underlined.

The Guest Editors wish to thank the Experiment@ International Conference 2011 main sponsor, Calouste Gulbenkian Foundation, Portugal.

A word of gratitude is also due to the University of Porto and to its Faculty of Engineering, to the University of Coimbra and to its Faculty of Sciences and Technology, to Ordem dos Engenheiros da Região Centro and to the Associated Laboratory of Aeronautics, Energy and Transports, all Portuguese Institutions. We also thank to all the Collaborating Institutions: IAOE and IGIP in Austria and SPEE, MTBrandão, Santander Totta, Unicer and Fundação para a Computação Científica Nacional in Portugal.

The last thanks go to the Editor-in-Chief of the International Journal of Online Engineering (iJOE), Prof. Michael E. Auer.

The Guest editors,

Maria Teresa Restivo, Faculty of Engineering of University of Porto and LAETA

Alberto Cardoso, Faculty of Sciences and technology of University of Coimbra 


\section{GUEST EDITORIAL}

\section{References}

[1] Farah Said, Benachenhou Abdelhalim, Neveux Guillaume, Barataud Denis: "Design of a flexible hardware interface for multiple remote electronic practical experiments of virtual Laboratory", Int. J. of Online Engineering (iJOE), Vol. 8, S2, March 2012, pp. 7-12, http://dx.doi.org/10.3991/ijoe.v8iS2.2004

[2] Nils Crabeel, Betina Campos Neves, Benedita Malheiro : "RemoteLabs Platform”, Int. J. of Online Engineering (iJOE), Vol. 8, S2, March 2012, pp. 13-18, http://dx.doi.org/10.3991/ijoe.v8iS2.1900

[3] Manuel Travassos Valdez, Carlos Machado Ferreira, Fernando Pires Maciel Barbosa : "Software Packages to Support Electrical Engineering Virtual Laboratories", Int. J. of Online Engineering (iJOE), Vol. 8, S2, March 2012, pp. 19-23, http://dx.doi.org/10.3991/ijoe.v8iS2.1917

[4] Lena Claesson, Lars Håkansson: "Using an online remote laboratory for electrical experiments in upper secondary education" , Int. J. of Online Engineering (iJOE), Vol. 8, S2, March 2012, pp. 24-30, http://dx.doi.org/10.3991/ijoe.v8iS2.1941

[5] Pavel Petrovič , Richard Balogh: "Experiences from Deployment of Remotely-Accessible Robotics Laboratory" , Int. J. of Online Engineering (iJOE), Vol. 8, S2, March 2012, pp. 31-35, http:/dx.doi.org/10.3991/ijoe.v8iS2.1958

[6] Valentim Sousa, Paulo Ferreira, Manuel Gericota: "Hey Fellows, We Shrunk the Server” , Int. J. of Online Engineering (iJOE), Vol. 8, S2, March 2012, pp. 36-41, http://dx.doi.org/10.3991/ijoe.v8iS2.1960

[7] Maria Graca Rasteiro, Maria Graca Carvalho, Abel Ferreira, Cristina B Gaudencio, Jose Granjo: "Using a Web Platform Developed for the Teaching of Chemical Processes to Reach Secondary School Students”, Int. J. of Online Engineering (iJOE), Vol. 8, S2, March 2012, pp. 4248, http://dx.doi.org/10.3991/ijoe.v8iS2.1982

[8] Alberto Cardoso, Miguel Vieira, Paulo Gil: "A Remote and Virtual Lab with Experiments for Secondary Education, Engineering and Lifelong Learning Courses”, Int. J. of Online Engineering (iJOE), Vol. 8, S2, March 2012, pp. 49-54, http://dx.doi.org/10.3991/ijoe.v8iS2.1984 